\title{
An Overview of Organizational Climate in Bhakra Beas Management Board
}

\author{
Suresh Kumar \\ Department of Commerce, Govt. Degree College Bhoranj (Tarkwari), Hamirpur, (Himachal Pradesh) India \\ suresh.commerce@gmail.com
}

\begin{abstract}
The present investigation is an attempt to understand the organizational climate perceptions of employees and to compare and contrast the perceptions regarding organizational climate in bhakra Beas management board. The study was conducted on 360 respondents belonging to the four different units in the organization. It was generally observed that there is no much difference in perceptions of employees regarding organizational climate. The description survey research design was considered suitable. The primary data was collected by employing an adopted questionnaire method. The respondents opinion towards perceptions has been found unequally distributed. The means difference in perceptions group also found significant.
\end{abstract}

\section{Keywords: Organizational Climate, Dimension, Perception.}

\section{Introduction}

Organization is the structure or network of relationship among individuals and positioned in a work setting and the process by which the structure is created, maintained and used. Climate refers to the entire internal environment of the Organization in which people of the Organization work for the achievement of goals. Organization climate acts as a bridge which links two type of phenomenon; on the one side the objective i.e., the tangible aspects of the organization e.g. structure ,rules, procedures and leadership style and on the other ,the moral and behavior of employees. It is defined as a molar concept that reflects the general atmosphere of a work place, and is assumed to influence the motivation, satisfaction and behavior of the individual in the organization. Organizational Climate is the summary perception which people have about an organization. It is a global expression of what the organization is. Organizational climate is the manifestation of the attitudes of organizational members toward the organization itself. An organization tends to attract and keep people who fit in its climate, so that its patterns are perpetuated at least to some extent. Human religionists introduced the concept of organizational climate in the late 1940s. Climate for an organization is somewhat like personality for a person. "Just as every individual has a personality that makes each person unique, each organization has an organizational climate that clearly distinguishes its personality from other organizations (James \& Milbouem, 1980).

Since 1966, there have been intensive and diverse efforts to conceptualize measures and utilize the organizational climate construct. A need to analyze the state of knowledge with respect to this construct exists currently because of contradictory thereof and research findings. Now a day, it has become an important aspect for describing the social system prevailing in an organization. Organizational climate is a quality of internal environment that is experienced by its members and influence their behavior. An organization tends to attract and keep people on the basis of climate available. Hence, the organizational climate is necessary to investigate and take some corrective measures for improving it, if needed. For the propose of present investigation the study has been confined to Bhakra Beas Management Board which is a joint collaboration of undivided states of Punjab and Rajasthan known as Bhakra Nangal \& Beas project. The study has been conducted during 2008 to 2010. The objectives of the study are

- To assess the employee's perceptions regarding organizational climate prevailed in Bhakra Beas Management Board.

- To compare and contrast the perception regarding organizational climate by employees.

- To determine the significant difference in favorable and unfavorable perception group.

\section{Review of Literature and Hypothesis Formulation}

The organization is looked at as a system of complete relationship among human and physical resources and work cemented together in a network of systems. The word 'climate' is used to designate the quality 
of good relation, the development of the individual. Schneider (1985) has prepared a working definition of climate, "Climate Perceptions are psychologically meaningful molar descriptions that people can agree characterize a system's practice and procedures and system may create many climates". Hellriegal and Slocum (1979) defined organizational climate as a set of attributes which can be perceived about a particular organization and/or its sub systems, and that may be induced in the way that organization and/or its sub systems deal with their members and environment. Forehand and Glimer (1964) have defined organizational climate as a "set of characteristics that describe and organization from and that, (a) distinguish one organization from another, (b) are relationship over a period of time, and (c) Influence the behavior of people in organization". According to Vroom, Organizational climate is the human environment within which organization's employees do their work.

Pareek (1975) has developed a scale to measure organizational climate which is best suited to Indian conditions. It is known as motivational analysis of organizational climate questionnaire Mao(c) and patterned after Litwin and Stringer's (1968) climate questionnaire. However, it differs from Litwin and Stringer's (1968) questionnaire in that (i) it is comparatively more exhaustive, and (ii) it uses ranking method rather than the rainy method used in Litwin and Stringers questionnaire. Climate is assessed in terms of achievement, expert power, extensions, affiliations, dependency, and control in twelve areas, namely, orientation, inter-personal relationship, supervision, managing problems, managing mistakes, managing conflicts, communication, decision making, trust, managing reward, risk taking, innovation and change. Kandan (1985) the study aimed to investigate, "Perception of Organizational Climate and Need Satisfaction among Bank Employees". It was observed that in all the needed area there was a perceived deficiency in fulfillment of social and security needs. These needs were comparatively more fulfilled than the higher order needs like self-actualization and self-esteem. Gani and Faruq (2001) aimed a study to investigated correlates of organizational climate in banking industry.

During the last three decades, no trend has been more dynamic in the industrial psychology then the growth of interaction in the Organizational Climate. The present study conducted in the banking industry of Kashmir, provides an adequate description of the concept, constructs, determinants and correlates of organizational climate. Natrajan (2001) concluded a study on organizational climate and teacher morale. The aim of the study was to find out the relationship between the school organizational climate and morale of teachers. The study revealed that in the elementary schools teachers, morale was high in open climate and there exist significant relationship between organizational climate and teacher's moral. Aggarwal and Bose (2004) examined the relationship between certain aspects of the organizational climate that may be created with the perception of procedural justice in public and private sector Indian organization and role efficacy. Findings indicated that irrespective of the form of the organization, managements attempt to develop the role efficacy of members. It required the creation of positive work environment which enables members to perceive fair procedures used for implementing human resource decisions. Doe and Orly (2008) presented a model that combine transformational and social interaction as antecedents of climate strength, (i.e. the degree of within-unit agreement about climate perceptions).Dispute over their longstanding status as primary variables, both antecedents have received limited empirical research Results indicated a partially mediated model between transformational leadership and climate strength, with density of group communication network as the mediating variable.

\section{Hypothesis Formulation}

Ho1: In general employees have perceived organizational climate as unfavorable.

Ho2: There would not have any significant difference among organizational climate Perceptions.

Ho3: Favorable and unfavorable organizational climate perceptions group has no influence on organizational climate scores.

\section{Research Methodology}

Research Design: The research design is the plan according to which the objectives are made and data assembled. It provides the empirical and logical basis for drawing conclusion and gaining knowledge. The descriptive survey research is considered suitable. The reason for selecting the destructive method of research was the just that it helps in generalization to a greater extent than the experimental research design 
Data Used: For accomplishing the objectives of the present study both primary and secondary data of BBMB was utilized. Primary data has been collected by administrating the questionnaire. The selection of respondents was ultimately made on convenient - cum judgment method of non-probability sampling and the sample selection is shown in Table 1.

Table 1: Sample Selection from Existing Population of $B B M B$

\begin{tabular}{llll}
\hline Employees Categories & Sanctioned Strength & Existing Strength & Sample (5\%) \\
\hline A (officers) & 269 & 219 & $30^{*}$ \\
B (officers) & 409 & 290 & $30^{*}$ \\
C (Non-officers & 8183 & 6127 & 300 \\
D (Non-Officers) & 6175 & 4910 & $\mathrm{Nil}^{* *}$ \\
Grand Total & 15036 & 11546 & 360 \\
\hline
\end{tabular}

*Sample Selection based on 5\% from each category (subject to a minimum of 30 employees of each category). ${ }^{* *} \mathrm{D}$ ' category employees were excluded from population on the basis of pilot survey and nonresponse behavior of this category

Format of the Questionnaire: As for as the organizational climate inventory is concerned, a standard and pretested questionnaire was utilized after incorporating required refinement in language simplification and other required improvements. The utilized questionnaire was developed by Gani and Shah (2001).

Scoring Procedure: Organizational climate inventory was scored according to the response that subject had made on a five point scale viz. 'Very large extent' (5), 'Large extent' (4), 'some extent' (3), 'smaller extent' (2), 'Not at all' (1). Figures in parenthesis denoting their wheightage. The summated size on organizational climate inventory may range from 40 to 200 .

Validity and Reliability Estimate of the Instrument: The Content, item and construct validity of organizational climate facets were established. The construct validity of inventory was found very high which ranges from 0.82 to 0.84 . The construct validity supports the items to total correlation validity. Reliability of the instrument was justified firstly through the calculation of cronbach's alpha $(\alpha)$ coefficient (cronbach's the observed coefficient value of job satisfaction scale 0.9110) has been observed above the Nunnally \& Bernstein (1994) Criterion (0.70) hence could be classified as acceptable reliable instrument. Keeping in view the objectives and the nature of data required under study the questionnaire method for data collection and the help of Mathematical, Tabular, Graphical and the Statistical methods were used. Statistical analysis was performed through the SPSS -17 packages.

\section{Results and Discussion}

Assessment and Examination of Organizational Climate Levels: Here, an attempt has been made to present the picture of overall organizational climate perception of the employees. For this purpose, the score obtained from the employees, on all the dimensions were classified as discussed already in the previous chapter. As discussed that the questionnaire contains, 10 dimensions each with 4 items. The respondents were asked to rate their opinion regarding each item from 'very large extent' to 'not at all'. The scores were coded from 5 to 1 in order to rate to the questionnaire items as discussed earlier. The classifications process of perceptions to organizational climate perceptions is discussed in the Table-2.

Table 2: Index Of Organizational Climate Perceptions: An Analysis

\begin{tabular}{llll}
\hline Scores & Perceptions of Organizational Climate & No. of Employees & Percentage (\%) \\
\hline $160-200$ & Favorable & 53 & 14.70 \\
$120-159$ & Moderate & 235 & 65.30 \\
$40-119$ & Unfavorable & 72 & 20.00 \\
& Total & 360 & 100.00 \\
\hline
\end{tabular}

Note: Figures in parenthesis shows percentages.

Source: Data collected through questionnaire. 
Graph 1: Organizational Climate Perception Index

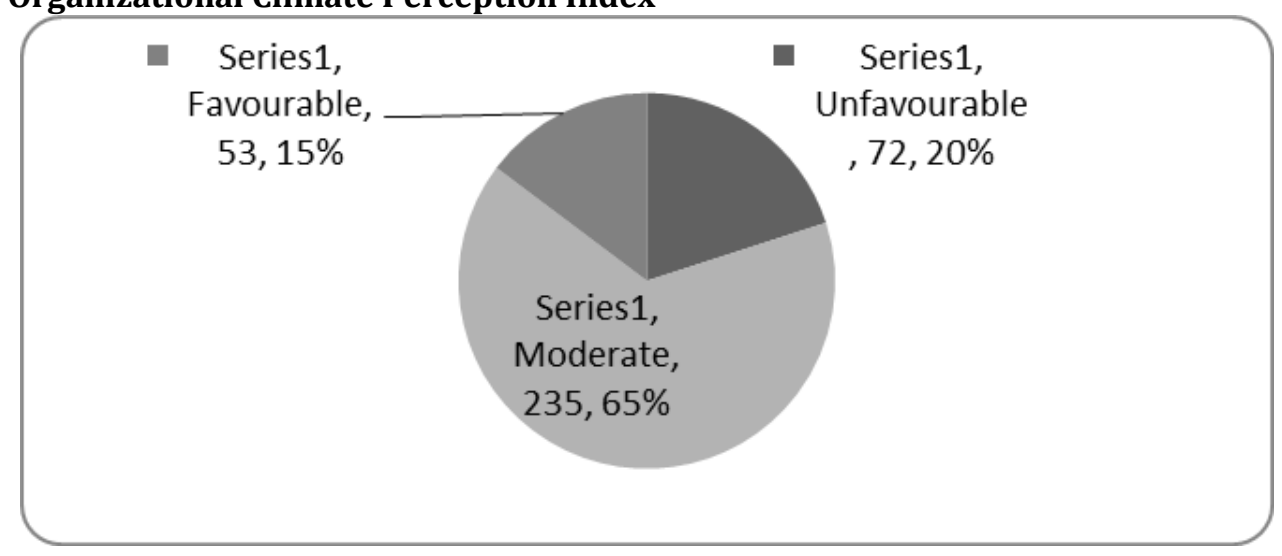

An examination of the information contained in the table 2 suggests that the majority of the respondents perceive moderate organizational climate. The score of the organizational climate is centrally located, thereby indicating thereby that the employees of BBMB perceive moderate organizational climate. Majority (65.3) of the employees showed a moderate degree of perceptions with regards to organizational climate. In comparison, a less percentage (14.7) tends towards favorable perception and still higher percentage (20) tends towards unfavorable perception regarding organizational climate in BBMB. A large section of the respondents have responded moderately towards organizational climate. A little percent of respondents have found lying on the extreme i.e., favorable (20 percent) and unfavorable perception (14). The above finding thus supports the Ho1 that in general employees have perceived unfavorable, Organizational Climate in the organization. The respondents opinion towards perceptions has been found unequally distributed. Thus, finding of table appears to be reasonably valid in view of the deplorable socio-economic conditions of workers and other factors influencing organizational climate.

Employees Perceptions towards Organizational Climate: The mean scores of the three groups (unfavorable, moderate and favorable organizational climate) perceptions were 105.36, 139.69 and 173.37 respectively. Two of the three classifications, which are of moderate and favorable perceptions scored above than the mean standard score i.e. 120. But the mean score of the unfavorable perceptions regarding organizational climate classification have observed low mean score (105.36) than the mean standard score. Further, the ANOVA technique has been used to know the analysis of variation between perceptions. The observed value to the ' $F$ ' Ratio was found more than the table value. Thus, it can be concluded that the means difference in the three groups was significantly classified according to their response towards organizational climate. Thus, the proposed null hypothesis (Ho2) may be rejected.

Table 3: Comparative Analysis of Organizational Climate Perceptions

\begin{tabular}{llll}
\hline Perception of Organizational Climate & $\mathbf{N}$ & Mean Score $(\bar{X})$ & Std. Deviation (o) \\
\hline Unfavorable & 72 & 105.36 & 13.60 \\
Moderate & 235 & 139.69 & 11.42 \\
Favorable & 53 & 173.37 & 11.03 \\
Total & 360 & 137.78 & 23.23 \\
\hline
\end{tabular}

Source: Data collected through questionnaire.

Table 4: Variance Analysis of Organizational Climate Perceptions

\begin{tabular}{llllll}
\hline Groups & SS & Df & MS & F Ratio & P-Value (Sig.) \\
\hline Between Groups & 143687.71 & 2 & 71843 & & \\
Within Groups & 49975.39 & 357 & 139 & 513.218 & .01 \\
Total & 193663 & 359 & & & \\
\hline Source & & & & & \\
\hline
\end{tabular}

Source: Data collected through questionnaire. 
Graph.2: Organizational Climate Perceptions Means Difference

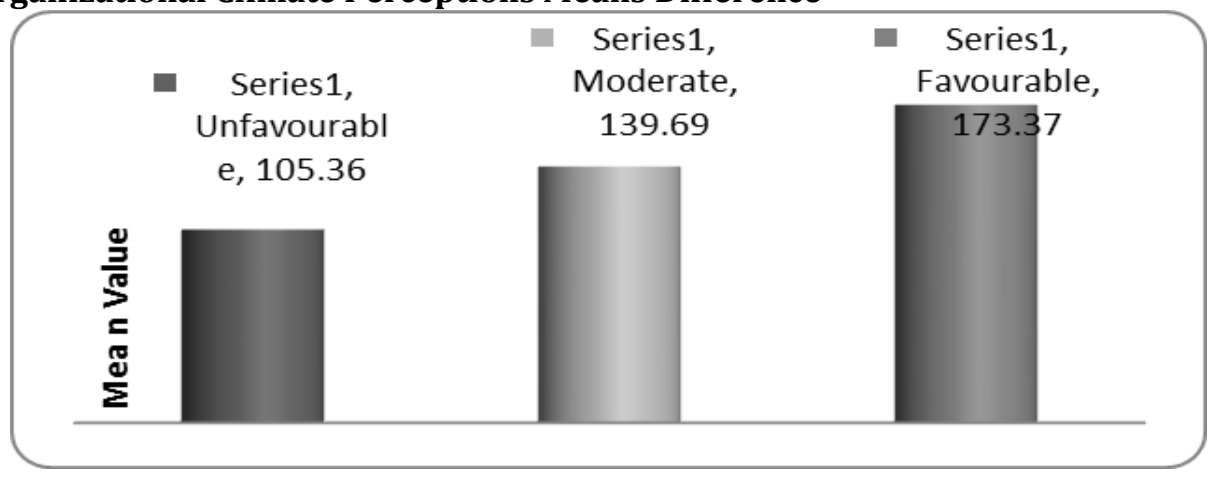

\section{An Analysis of Favorable and Unfavorable Organizational Climate Groups:}

An attempt has been made in this section to classify the respondents in two groups on the basis of observed score. The score on the scale ranges in between 40 to 200 . The neutral score on the scale is 120 $(40 \times 3)$. The score equal to or above the neutral point perceive favorable organizational climate and the scores equal to the neutral score 119 and lower value assumed unfavorable organizational climate in the organization. The mean score of the favorable organizational climate and the unfavorable organizational climate perceptions along with ' $t$ ' test has been presented in table. The ' $t$ ' test was applied to test whether these two mean scores of two above mentioned groups were significantly different or not.

Table 5: Comparative Analysis of Organizational Climate Perceptions

\begin{tabular}{llllll}
\hline Organizational Climate Perceptions & $\mathbf{N}$ & $\begin{array}{l}\text { Mean } \\
(\bar{X})\end{array}$ & $\begin{array}{l}\text { S.D } \\
(\boldsymbol{\sigma})\end{array}$ & 't' Value & P-value \\
\hline Unfavorable Organizational climate & 72 & 105.36 & 13.59 & 18.49 & $<0.01$ \\
Favorable Organizational climate & 288 & 145.89 & 17.30 & & \\
\hline
\end{tabular}

Source: Data collected through questionnaire.

\section{Graph 3: Employees Distribution in Favorable and Unfavorable Organizational Climate Groups}

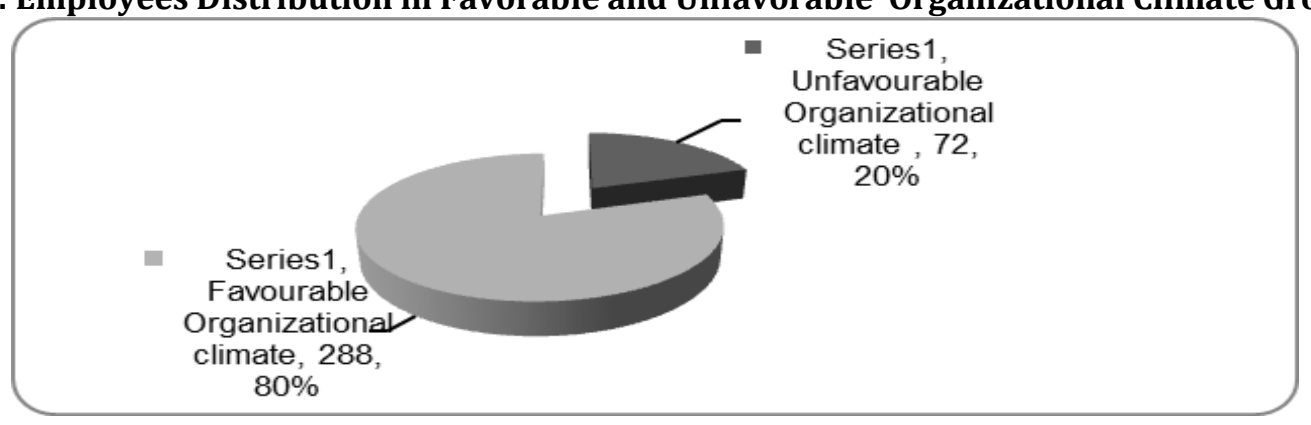

The mean score (145.89) of those, who perceive organizational climate favorable was greater than the mean score (105.36) of those who have perceived unfavorable organizational climate. The mean score of unfavorable organizational climate is lower than mean standard or neutral score i.e., 120. Out of 360 respondents from the sample, only 72 respondents perceive un-favorable organizational climate whereas 288 respondents perceive favorable organizational climate. The obtained ' $t$ ' value $(t=18.49)$ was highly significant even at 1 percent level of significance, which accept the alternate hypothesis in this regard. Thus, on the basis of above analysis, it can be concluded that most of the respondents have perceived favorable organizational climate in Bhakra Beas Management Board.

\section{Conclusion}

Organizational climate perceptions assessments have revealed shocking picture with only in 14.70 percent respondents fall in the favorable organizational climate perceptions. The organization should give special priority to find the reasons for perceiving moderate organizational climate perception in majority. The significant means score difference of these three perceptions suggests that the favorable 
means score was much higher from the other two groups. Hence, the moderate organizational climate perceived employees should be converted to favorable perceptions. The routine decisions should be taken by regular meetings; management should consult employees and the logical and fair mechanism to be developed for converting the unfavorable perceptions to favorable. An unfavorable and favorable organizational climate perception classification mean difference was also found significant. It emphasis the need to improve the unfavorable perception to the favorable perceptions because the unfavorable perception group have a mean score below the standard mean score significantly.

Limitations of the Study: To complete the present research work no stone has been left unturned in view to make it best possible work. Non-probability method of sampling, stringency of time, resources, and the incomplete and non-responses of certain items may lose the tools authenticity. The concept of Organizational Climate Perception is not entirely specific even though efforts have been made to use it in the present study to meet our purpose. The rating method of Organizational Climate rating is not a full proof method. Despite of these limitations all precautions have been made in order to make its impact negligible on the research results and findings.

Identification of Area for the Further Research: A number of studies including the present one have been conducted on Organizational Climate the public and private sector. The present study has been conducted for the realization of certain objectives. Though, every attempt has been made to make the study comprehensive besides, certain areas have still remained unexplored. Organizational Climate is a culture specific exercise. Its form and contrast very with prevailing socio-economic, cultural and technological milieu of a country.

\section{References}

Aggarwal, M. \& Bose, S. (2004). Organizational Climate for Perceptions of Procedural 'Fairness' in Human Resource Practices and Role Efficacy. Indian Journal of Industrial Relations, 40(2): 176-196.

Doe, Z. \& Gazit, T. (2008). Transformational leadership and Group Interaction as climate Antecedents: A Social networks analysis. Journal of Applied Psychology, 93(4): 744-757.

Forehand, G., \& Gilmer, B. (1964). Environmental variation in studies of Organizational Behavior. Psychological Bulletin, 22: 361-382.

James, G. \& Milbouem, G. (1980). Human Behavior in the Work Environment: A Managerial Perspective. Goodyear Publishing Company, 92.

Gani, A. \& Shah, F. A. (2001). Correlates of Organizational Climate in Banking Industry. Indian Journal of Industrial Relations, 36(3): 301-322.

Hellriegal, D. \& Slocum, W. J. (1979). Organizational Climate, Measures, Research and Contingency. Academy of Management Journal, 17(2): 255-280.

Kandan, M. (1985). Perception of Organizational Climate and Need Satisfaction among Bank Officers. Indian Psychological Review, 29: 1-5.

Litwin, G., \& Stringer, R. (1968). Motivation and Organizational Climate, Cambridge Mass: Howard Uni. Press.

Natarajan, R. (2001). A Study of Organizational Climate and teacher Morale. Journal of Psychological

Research, 45(1): 19-23.

Nunnally, J. C. \& Bernstein, I. H. (1994). Psychometric Theory (3rd Ed.). New York: McGraw-Hill.

Pareek, U. (1975). Motivational Climate Questionnaire, Monographed Report Indian Institute of Management, Ahmadabad.

Schneider, B. (1975). Organizational Climates: An Essay, Personnel Psychology, 28(4): 447-479. 